\title{
Lithospheric thinning under the Araripe Basin (NE Brazil) from a long-period magnetotelluric survey: Constraints for Tectonic Inversion
}

\author{
Xavier Garcia ${ }^{1}$ \\ Institute of Marine Sciences, CSIC. Pg. Marítim de la Barceloneta, 39-47, 08003, \\ Barcelona, Spain \\ Jordi Julià \\ Departamento de Geofísica \& Programa de Pós-Graduação em Geodinâmica e Geofísica, \\ Universidade Federal do Río Grande do Norte, Natal 59072-970, Brazil \\ Ana M. Nemocón \\ Programa de Pós-Graduação em Geodinâmica e Geofísica, Universidade Federal do Río \\ Grande do Norte, Natal 59072-970, Brazil \\ Maik Neukirch \\ Institute of Earth Sciences Jaume Almera, CSIC, Barcelona
}

Abstract

The lithospheric architecture of the western Borborema Province and northern São Francisco craton of NE Brazil has been investigated through analysis of long-period magnetotelluric data acquired along a $700 \mathrm{~km}$ long survey, using 12 instruments. The survey samples several tectonic terrains in the Province and penetrates into the adjacent São Francisco craton after crossing the Araripe Basin, an aborted rift basin filled with Mesozoic sediments that peak at $\sim 1000 \mathrm{~m}$ above mean sea level. High conductivities are observed at shallow depths under the main Precambrian shear zones that pervade the Province - consistent with tectonic reactivation - and as a 
small patch embedded within the high resistivities that characterize the São Francisco craton. High conductivities $(\sim 25 \Omega m)$ are also observed below $120 \mathrm{~km}$ depth between the Patos and Pernambuco Lineaments - right under the Araripe Basin - flanked by resistive $(>120 \Omega m$ ) material immediately to the north and south. This deep, highly conductive body is found consistent with the presence of melt and aqueous fluids, and is interpreted as shallow asthenospheric mantle bounded by thicker lithosphere. We propose that extensional stresses in the Mesozoic stretched and thinned the lithosphere under the Araripe Basin, causing passive upwelling of asthenospheric material and lateral flow of the overlying lithosphere, and resulting in thickening of the lithosphere under the flanks and uplift of the Araripe Basin. We also hypothesize that thermal weakening of the lithospheric mantle - perhaps sustained by channeling of asthenospheric flows under the basin - would have caused regional stresses to concentrate in the brittle upper crust and contribute to basin inversion. We thus propose that a combination of localized horizontal stresses and vertical buoyancy from underlying asthenospheric material are ultimately responsible for the actual topography of the Araripe Basin. Keywords: Araripe Basin, Borborema Province, Magnetotellurics, Conductivity, Lithosphere, Asthenosphere, Basin inversion, Partial melt

\section{Introduction}

The Borborema Province is the remnant of a larger Neoproterozoic mobile belt that is presently located between the São Francisco craton, the Parnaíba Basin and the coastal sedimentary basins of NE Brazil. It is generally regarded as composed of a series of Archean to Proterozoic tectonic blocks sep- 
45 Neto et al., 2017).

46 Intraplate uplift is best expressed through the high topography of the 47 Borborema Plateau to the east and the Chapada do Araripe (Araripe Basin) 
to the West. The Borborema Plateau is a NE-SW elongated topographic feature with maximum elevations of $\sim 1200 \mathrm{~m}$. Its elevation has traditionally been attributed to tectonic uplift resulting from either thermal doming (Ussami et al., 1999; Jardim de Sá et al., 1999) or isostatic uplift (Morais Neto et al., 2009; Oliveira and de Medeiros, 2012), although recent studies suggest it might be a high-standing, rheologically strong feature (Almeida et al., 2015; Luz et al., 2015; Simões Neto et al., 2017). The Chapada do Araripe, on the other hand, is elongated in the EW direction and can be described as an aborted rift basin that lies at $\sim 1000 \mathrm{~m}$ altitude. Its main development has been attributed to the breakup of Pangea (Assine, 2007; de Matos, 1999), and the proposed mechanisms for its actual elevation revolve around topographic inversion - in which regional uplift of the Province would have been followed by differential erosion (Peulvast and Bétard, 2015) - and basin inversion driven by EW compression from the Mid-Atlantic Ridge and Andean pushes (Marques et al., 2014).

The magnetotelluric (MT) method is a geophysical technique used for imaging the electrical conductivity of the Earth's crust and upper mantle. It is a passive electromagnetic method that uses the propagation of the natural electric and magnetic fields through the conductive subsurface. Simultaneous measurement of electric and magnetic fields in orthogonal directions at the Earth's surface allow inference of subsurface electrical conductivity variations from tens of meters to hundreds of kilometers depth (Chave and Jones, 2012). The electrical resistivity - or its reciprocal, the electrical conductivity - is the most variable of all geophysical rock properties; variations of eight orders of magnitude can be encountered in the Earth, and of several orders 
73 of magnitude within the same rock type. The electrical resistivity of subsur-

74 face rocks typically varies between $10^{-2} \Omega m$ and $10^{6} \Omega m$. The MT method 75 is widely utilized to study the subsurface at crustal and lithospheric scales. Conductivity maps obtained by MT studies are used to detect interconnected fluids, discriminate between different geological formations, map-faulted areas, and detect lithospheric conductivity anomalies related to tectonic processes. These results, associated to geological observations and geophysical models, allow to image the structure of the lithosphere and to interpret them geodynamically.

Here, we present results from a long-period MT survey spanning for $\sim 700 \mathrm{~km}$ in the NS direction across the western Borborema Province and northern São Francisco craton of NE Brazil, the BODES ${ }^{2}$ experiment. The MT installation sites were selected to be in close proximity to a deep, passivesource seismic deployment representing the seismic component of a multidisciplinary study led by the Laboratório Sismológico of the Universidade Federal do Rio Grande do Norte (LabSis/UFRN). The goal of the BODES experiment is to build integrated geophysical images of the Province's crust and lithospheric mantle in order to improve our understanding of its geodynamic and tectonic evolution.

\footnotetext{
${ }^{2}$ BODES: BOrborema Deep Electromagnetic and Seismic
} 


\section{Data acquisition and galvanic distortion analysis}

93

\subsection{Data acquisition and processing}

In May and October of 2015, a total of 11 instruments were installed along a profile ranging from Pedra Branca in Ceará state to Ponto Novo in Bahia state (Figure 1). In 2017 the MT profile was extended with two additional stations, resulting in a total length of about $700 \mathrm{~km}$ and a final station spacing of roughly $60 \mathrm{~km}$. Given the decay of lateral sensitivity, we expect a poor constraint of any of the structures of the upper crust other than the ones located directly underneath the instruments. We used long-period MT instruments (LEMI), borrowed from the Pool de Equipamentos Geofísicos do Brasil (PEGBR), together with non-polarizable $\mathrm{Cu}-\mathrm{CuSO}_{4}$ electrodes. The instruments recorded between 21 and 34 days at a sampling rate of $1 \mathrm{~Hz}$. The registered electromagnetic time series were in general of very good quality, only displaying noisy sections at a few sites. Northeast Brazil is extremely dry and although precautions were taken to prevent electrodes from drying out, a few days of data were still lost at some locations. Time series sections affected by electrode problems were disregarded from further analysis.

In MT, the processing stage consists of the calculation of the electromagnetic transfer functions or responses by means of robust regression algorithms. The electric $E$ and magnetic $H$ fields are related through the impedance tensor $Z$ in the frequency domain, according to:

$$
\left(\begin{array}{c}
E_{x} \\
E_{y}
\end{array}\right)=\left(\begin{array}{cc}
Z_{x x} & Z_{x y} \\
Z_{y x} & Z_{y y}
\end{array}\right)\left(\begin{array}{c}
H_{x} \\
H_{y}
\end{array}\right),
$$

and the tipper vector is the transfer function between the vertical and hori- 
zontal magnetic field, expressed in the frequency domain as:

$$
H_{z}=\left(\begin{array}{cc}
A & B
\end{array}\right)\left(\begin{array}{c}
H_{x} \\
H_{y}
\end{array}\right) .
$$

The tipper and impedances are the MT transfer functions or responses. In particular the impedance tensor is expressed as amplitudes (apparent resistivities, $\left.\rho_{i j}\right)$ and phase $\left(\phi_{i j}\right)$ :

$$
\rho_{i j}=\frac{1}{\omega \mu}\left|Z_{i j}\right|^{2}, \quad \phi_{i j}=\tan ^{-1}\left(\frac{\Im Z_{i j}}{\Re Z_{i j}}\right),
$$

where $\omega$ is angular frequency, $\mu$ is magnetic permeability, and the subindexes $i$ and $j$ indicate the impedance tensor elements.

To process the MT time series we used the multi-remote reference EMT code (Neukirch and Garcia, 2014). This code is particularly useful when nonstationary noise is present, and a few of the sites were particularly noisy. The remote references were chosen to be stations that recorded simultaneously. In general, the responses were found to be of good quality between $8 s$ and $20,000 s$. Some sites were affected by low solar signal, which impacted mainly the longer periods. In addition, the electrodes used to estimate the electric field are known to decay performance for long-term deployments and, for this reason, estimates beyond 20,000 s were deemed unreliable. Responses were rotated during this initial processing stage to the geographic north reference system from the magnetic north acquisition convention. Site B11 was occupied $22 \mathrm{~km}$ northwest of site B01 because the latter was severely affected by strong distortion effects. After processing, site B11 responses were nonetheless similar to B01 and noisy; therefore site B11 was discarded and B01 was finally used in the modeling stage in order to keep a more regular distance between sites during the inversion process. 
In the MT method, the skin depth estimation has traditionally been used to assess the depth of penetration of a survey. Using the skin depth estimation and the responses from the BODES experiment, the period range covered in this survey is sufficient to image the lithosphere. Given the good lateral resolution of the MT method (Jones, 1987), our station spacing allows to cover lateral changes in resistivity on a regional scale.

\subsection{Galvanic Distortion Analysis}

Subsurface heterogeneities below the scale of our experiment can cause galvanic distortion (Jones, 2012), which can hinder the interpretation of the modeled responses. Several algorithms are available to correct for galvanic distortion and at the same time estimate the electric strike angle of the structures. To analyze the BODES dataset we utilized the gadget algorithm (Neukirch et al., 2017), which does not assume any a priori dimensionality about the data. The gadget algorithm decomposes the impedance tensor into the well-known phase tensor (Caldwell et al., 2004) and the recently introduced Amplitude tensor (Neukirch et al., 2017). The later is used to recover the galvanic distortion parameters as originally parameterized by Groom and Bailey (1989). Table (1) contains the estimated distortion parameters of the BODES dataset; in general, high distortion parameters (large twist and shear angles) can be appreciated, which are indicative of strong distortion. The strongest galvanic anisotropic distortion is found to the north of the Araripe Basin, and corresponds to the location of the Patos and Jaguaribe-Tatajuba shear zones, together with an array of local-scale faults (Peulvast and Bétard, 2015). The elliptic shape of the amplitude tensor parameters is an indication of electrical anisotropy, where the strongest the anisotropy the more elliptical 
the shape becomes (Neukirch et al., 2017).

The amplitude, phase tensor electrical strike angles and induction arrows (real part) are displayed in Figure (3) for different increasing periods (increasing depth of penetration). This figure shows that even at the longest periods shown here (corresponding to lithospheric depths) there is no common electric strike angle for all periods and all sites. The plot also shows the main shear zones in the study area. Considering the 90 degrees ambiguity in MT when dealing with the strike angle, the correlation of the phase tensor strike angle with the shear zones (red lines) for shorter periods becomes apparent. The galvanic distortion and strike angle analysis reflect the complex geological and tectonic history of the Borborema Province, which is crisscrossed by a network of deep shear zones that likely extend down into the lithospheric mantle (Tommasi et al., 1995). Large distortion effects are also observed south of the profile, mostly at site B08, and towards the end of the profile, coincident with the surface expression of a NS trending shear that marks the western edge of the Chapada Diamantina (within the São Francisco craton). The induction arrows point towards areas of enhanced conductivity. For shorter periods, these arrows focus on local structures, while for longer periods, they point out towards the East. Induction arrows pointing outside the profile, confirms that the geo-electrical structure under the western Borborema Province is 3D. 


\section{MT data modeling}

\subsection{Inversion approach}

To develop the model that best explains the observations, we employed the ModEM 3D inversion code (Kelbert et al., 2014). This code uses a parallelized forward iterative solver on a finite difference grid and a non-linear conjugate gradient algorithm for the inversion.

We considered the full impedance tensor and tipper during the inversion process for our 12 sites, and the responses were decimated to 5 frequencies per decade - from $9 s$ to $20,000 s$. We assumed an error threshold of $3 \%$ for impedances, and a 0.03 absolute error for the tipper. We also masked obvious spurious responses before inversion, so they were not taken into account. The mesh size was $155 \times 47 \times 49$ blocks, with $5 \mathrm{~km}$ size blocks around the center of the model. Any of the inversion calculations took between 3 to 4 days on a 16 core cluster node, involving some 150 iterations.

During the inversion process, we experimented with a number of homogeneous (1D) starting models, each with different values of resistivity. The results showed a very strong dependence on the starting models, which we attribute to the data being acquired along a linear profile. Our preferred results were obtained with a starting model consisting of a $200 \Omega m$ half-space overlaying a $50 \Omega \mathrm{m}$ bottom layer at $130 \mathrm{~km}$ depth. Most importantly, we had to account for bathymetry in our inversions due to the close proximity of the Atlantic Ocean on the east and north sides of the model (see plot in Figure 2). For this, we used the GEBCO database ${ }^{3}$. Attempts to invert the

\footnotetext{
${ }^{3}$ The GEBCO_2014 Grid, version 20150318, http://www.gebco.net
} 
data without including the ocean failed to reach a reasonable fit, yielding RMS misfits larger than 4.5. Additionally, to avoid introducing artifacts, we started by inverting the shorter period data and, after reaching a misfit RMS of 2 or lower, we proceeded to invert the full period-range of the MT response. We tried different approaches and starting models to invert this dataset (see the Supplementary Material section for a summary of our efforts). Our preferred model was chosen because it contained more realistic features, which could be interpreted in a geological manner.

The misfit of our preferred inverted model is 2.23 (see individual site fits in the Supplementary Material section), which fits the apparent resistivities, phases, and tipper vector reasonably well. We checked the robustness of the final model by removing specific features (changing resistivities) and numerically assessing whether they are required to fit the data. Our sensitivity tests indicate that all structures present in our preferred model are required, and that the distribution of electrical resistivity in the final model is robust.

\subsection{Modeling results}

Figure (4) displays the best model obtained after inversion of the MT observations. The 3D block has been cut along the surface profile to show the most relevant structures sensed by our data. Blue, cold colors indicate resistive structures, while red, warm colors signal conductive structures. The most striking feature is the deep conductor starting at about $120 \mathrm{~km}$ depth under the Araripe Basin, between the Patos and Pernambuco lineaments (C1 in Figure 4). Its resistivity is less than $30 \Omega m$, and both the location and resistivity are very robust features in the inverted model.

To the north and south of conductor $\mathrm{C} 1$, and also at lithospheric depths, 
we find a number of resistive structures (R1, R2 and R3 in Figure 4). Structure $\mathrm{R} 1$ is located in the northern tip of the profile and reaches depths of $200 \mathrm{~km}$. To verify that this structure is not a border effect, we recorded an additional site in Spring 2017 (site B10) more to the north. This additional observation confirmed that the thick, resistive structure is robust and not an artifact of the inversion process. Interestingly, the location of the resistive structure R1 correlates with the presence of the exposed Archean rocks (Figure 2) of the Troiá massif (Fetter et al., 2000). Structure R2, immediately south of the Araripe Basin, is also imaged as a thick, resistive structure. And, to the south, coinciding with the location of the São Francisco craton, the model also shows a thick, resistive structure (R3), reaching more than $180 \mathrm{~km}$ depth.

At shallower, crustal levels a number of conductive structures can be identified. The conductive structure C2 (Figure 4) starting at $10 \mathrm{~km}$ depth under site B08 is located on the limit between the Riacho do Pontal fold belt and the Chapada Diamantina (northwest of the São Francisco craton). Between sites B01 and B02, there is a strong conductive anomaly, although we do not have the coverage to interpret it. This conductor correlates with the surface expression of the Jaguaribe-Tatajuba lineament, and was also reported in an independent MT profile located east of the BODES profile (Padilha et al., 2014, profile A-A'). Conductor C3, under site B03, correlates with the Patos lineament and, as appreciated in Figure (4), is marked as a nearly horizontal upper crustal structure. Finally, conductor C4 is located under the Riacho do Pontal fold belt. 


\section{Discussion}

\subsection{Shear Zone reactivation, fluids and mineralization}

A number of conductive bodies characterize the shallow (crustal) structure along the MT section displayed in Figure 4. Conductor anomalies C2 and $\mathrm{C} 4$ are located on the northern boundary of the São Francisco craton, south and north, respectively, of the contact between the Cariris Velhos belt and the Riacho do Pontal fold belt. The Riacho do Pontal fold belt has been described as a continental-scale $(1000 \mathrm{~km})$ accretion belt that assembled during the Braziliano orogeny $(\sim 600 M a)$, together with the Rio Preto and the Sergipano fold belts. Moreover, the accretion process would have been marked by south-bound subduction north of the Cariris Velhos (Caxito et al., 2014), and north-bound subduction to the south (Caxito et al., 2016). Indeed, the Riacho do Pontal fold belt presently contains the remains of Neoproterozoic oceanic crust. Conductors associated to subducting zones have been previously reported in the Borborema Province (Padilha et al., 2017), and interpreted as caused by the presence of metals in folds or interconnected graphite. Given the presence of sulphide mineralization and graphite in the Riacho do Pontal area (Caxito et al., 2014), we thus interpret both conductors $\mathrm{C} 2$ and $\mathrm{C} 4$ as caused by either conductive minerals or graphite deposited by subducting oceanic lithosphere along this former passive margin.

Conductor C3 (Figure 4), which coincides with the location of two major shear zones in the Borborema Province, is interpreted as the extension of those shear zones deep into the crust. This implies that shear zones in the Borborema Province have been reactivated through time and have played a role in the accommodation of tectonic stresses. Indeed, the network of 
Precambrian shear zones has been proposed to have exerted key controls in the development of Mesozoic rift basins (de Matos, 1999) and during the episodes of tectonic uplift in the Araripe Basin (Marques et al., 2014) and the Borborema Plateau (Oliveira and de Medeiros, 2012). The origin of the conductive anomaly could then be the result of the percolation of meteoritic fluids at shallower depths, and the presence of conductive minerals and graphite precipitated by fluid flow.

\subsection{Shallow asthenosphere under the Araripe Basin}

Conductor $\mathrm{C} 1$ is the most prominent feature in the resistivity cross-section displayed in Figure 4. This conductive anomaly is coincident with a low velocity anomaly reported in a recent tomographic study (Simões Neto et al., 2017) that runs in the EW direction under the Araripe Basin at sub-lithospheric depths. Taken at face value, it suggests the presence of asthenospheric material at depths as shallow as $120 \mathrm{~km}$, and the presence of thin lithosphere under the Araripe Basin. Moreover, this conductive structure is located close to a marked heat flow anomaly (Davies, 2013) of $124 \mathrm{~mW} / \mathrm{m}^{2}$ (median value) on the eastern edge of the Araripe Basin. Although the heat flow map resolution for South America is on the order of $0.5^{\circ}$, the overall increase in heat flow would be consistent with asthenospheric material placed at $120 \mathrm{~km}$ depth. Alternatively, the alternative heat flow map of South America of (Hamza et al., 2005) does not display such a marked anomaly; however, it shows a positive anomaly that coincides with the northern extension of our profile. In any case, a thermal anomaly could also be caused by fluid release or radiogenic material within the crust.

The top of the asthenosphere at $120 \mathrm{~km}$ underneath the Araripe Basin, 
implies that the adiabatic temperature at that depth must be around $1350{ }^{\circ} \mathrm{C}$ (e.g., Till et al., 2010). Assuming a pressure at 4GPa, and considering the modeled resistivity of the top of the anomaly is $25 \Omega m$, thermobarometric models can be used to obtain resistivities for different mineral phases. For dry olivine - and therefore only assuming thermal effects - the SO3 model of Constable (2006) would yield a temperature of $1820^{\circ} \mathrm{C}$ for the resistivity observed. This is obviously too hot for an asthenosphere under a continent at $120 \mathrm{~km}$ depth for which no obvious rifting process is presently at play.

The addition of water and/or partial melt, however, could help reconcile the observed resistivity with a shallow asthenosphere, as both fluid and melt will increase conductivity. It has been suggested that the upper mantle and in particular the asthenosphere, contains between 50 to $200 \mathrm{ppm}$ of water (Green et al., 2010), which can cause low-temperature partial melting of the lithospheric mantle (Mierdel et al., 2007). In addition, some studies have suggested that the asthenosphere contains a small amount of partial melt, and recent work by Mancinelli et al. (2017) suggests that either rheological or melt gradients must be present at the lithosphere-asthenosphere boundary in order to explain the gradient of seismic velocities observed. Moreover, it has been recently suggested that mantle resistivity can reach $30 \Omega m$ at asthenospheric depths (Dai and Karato, 2009) by adding water, but it cannot be lowered below this value without adding so much water that melting is initiated (Ni et al., 2011).

Without further constraints, we consider that melt and water are responsible for the anomaly, and provide upper bounds for the amount of these fluids necessary to explain the observed anomaly $(\mathrm{C} 1)$. Considering the rela- 
tionship of (Ni et al., 2011, eq. 3) for the presence of water and melt phases for basaltic rocks under asthenospheric conditions, the upper bound HashinShtrikman (Hashin and Shtrikman, 1962) relationship and the constraints that we have for anomaly $\mathrm{C} 1$, we investigate the possible relationship between water amount and melt fraction for two host mineral resistivities (Fig. 5). A similar technique was used by Sarafian et al. (2015) to quantify the amount of melt and water in the central Pacific asthenosphere as part of the NoMelt project. The partition coefficient between mantle and melt is set to $D_{\text {mantle-melt }}=0.006$ Hirschmann et al. (2009); Ni et al. (2011). For the bulk value of the mantle resistivity ( $\sigma_{1}$ in eq. 3 in $\mathrm{Ni}$ et al. (2011)), we used a peridotite model (Sarafian et al., 2015) consisting of 60\% Ol (Wang et al., 2006), 35\% Opx (Dai and Karato, 2014) and 15\% Cpx (Zhao and Yoshino, 2016), hydrated by water left after partitioning with melt. By using a geometric average (Shankland and Duba, 1990) we estimate the overall conductivity of this peridotitic mantle. As mentioned earlier, for the final melt-hydrated periodotite, we use a HS+ model using the conductivities of peridotite and melt at each value of melt and water percentage. For the suggested values of water content in the upper mantle (50 to $200 \mathrm{ppm}$ ), we obtain that the melt fraction at $120 \mathrm{~km}$ depth under the Araripe Basin should be around $0.3 \%$, and $0.2 \%$ melt for an enriched mantle with $800 \mathrm{ppm}$ of water. These are reasonable amounts of water and melt amount in an asthenospheric mantle (Sifré et al., 2014).

What is then the origin of the $\mathrm{C} 1$ anomaly in the shallow asthenosphere under the Araripe Basin? Mesozoic extensional events were certainly responsible for initial thinning of the lithosphere and passive upwelling of the 
underlying asthenosphere. Why the shallow asthenosphere would have been preserved until today, however, requires further explanation. In general, the continental lithosphere is viewed as a dry environment, so hydration from melting of the overlying lithosphere seems unlikely. It has been suggested (Mareschal et al., 1995; Chen et al., 2009) that relict metasomatism can be preserved over billions of years in the cratonic lithosphere; however, that these metasomatic materials can provide enough fluids as the ones required by our model to keep the lithosphere thin since the Mesozoic seems more unlikely. Because of their capacity to bring fluids and other incompatible elements, plumes are very effective metasomatizing agents (e.g., Baker et al., 1998), in addition to bringing carbonitic melts that enhance conductivity, but there is no evidence of a plume recently passing under the Borborema province (e.g. Storey, 1995; Schimmel et al., 2003; Knesel et al., 2011; Pinheiro and Julià, 2014) since the Mesozoic. Alternatively, olivine, with a typical value of $50 \mathrm{ppm}$ of water storage capability (Dixon et al., 2002), could match our inferred water content; but somehow the asthenosphere would need to be preserved from freezing and thickening the lithosphere under Araripe.

At this point, we can only conjecture that lateral flow of hot, molten material could be responsible for preserving the shallow asthenosphere under the Araripe Basin. Rifting events during the Mesozoic in the Borborema Province might have created the path necessary for the melt to travel under the lithosphere. As mentioned earlier, seismic tomographic imaging of the Borborema Province's upper mantle has revealed a NE-SW trending low velocity channel - with an EW trending offshoot right under the Araripe Basin 
- that is consistent with lateral asthenospheric flow (Simões Neto et al., 2017). Due to proximity, a mantle plume under the Fernando de Noronha hotspot would be the most obvious candidate for feeding the postulated lateral flow under the Province (FNMA in Figure 2). Alternatively, it had been proposed that all intraplate volcanism in the Borborema Province younger than $85 \mathrm{Ma}$ is the result of lateral flow from a distant plume tail presently located under the Paraná basin (Sleep, 2003). Although lateral asthenospheric flow around the São Francisco craton has been invoked to explain seismic anisotropy patterns from SKS splitting observations (Assumpção et al., 2006), a clear connection between an active Paraná plume and the Borborema low-velocity asthenospheric channel would need to be established.

\subsection{Basin inversion and ductile flow}

A number of deep resistive anomalies to the north and south of the profile suggest the presence of dry, crystalline rocks in a thick lithosphere, typical of cratons. To the south (R3 in Figure 4) the anomaly is expected, as it would correspond to the São Francisco craton, and resistivities larger than $500 \Omega m$ are consistent with depleted, crystalline mantle rocks. However, resistive anomalies R1, at the northern tip of the BODES profile and R2, to the south of the Riacho do Pontal fold belt, are harder to explain.

Previous MT studies, nonetheless, had already shown a thick, resistive structure (Padilha et al., 2014, profile B-B') down to $100 \mathrm{~km}$ depth in the northwestern Borborema region. Although the authors focused on interpreting anomalies at shallow crustal levels, they did interpreted this enhanced electrical resistivity in the upper mantle to be the relic of dehydrated, sediment-depleted oceanic lithosphere that subducted during the Neoprotero- 
zoic. How this structure could have survived the vigorous thermal history of the NW Borborema Province is unclear; fortunately, the deeper constraints presented here allow for a more plausible interpretation of this enhanced resistivity.

Numerical modeling has suggested (Liu and Shen, 1998) that passive upwelling of the asthenosphere under the Colorado Plateau may have thinned the overlying lithosphere and thickened the flanking lithosphere under the Sierra Nevada through a roll down process. Similarly, mantle upwelling under the Araripe Basin might have developed the necessary lateral pressure gradients in the lithospheric mantle to push the overlying lithosphere sideways and towards the flanks, explaining the thickened roots immediately north and south of conductor C1 (features R1 and R2 in Figure 4).

Additionally, the lithospheric erosion under the basin implied in the rolldown model could provide a plausible mechanism to explain the tectonic inversion of the Araripe Basin. It has been proposed that tectonic inversion of the Araripe Basin was due solely to compressional stresses developed from the pushes of the Mid-Atlantic Ridge and the Andean front (Marques et al., 2014). The problem with the model proposed by Marques et al. (2014) is that the high-angle faults bounding the basin make it difficult to think of pure horizontal compression as a viable uplift mechanism. Interestingly, it has been observed (Assumpção et al., 2004) that intraplate seismicity occurs preferentially on crust above thin lithosphere, suggesting that stresses concentrate above lithospheric "thin spots". If our interpretation is correct, the lithosphere is thin under Araripe Basin, vertical buoyancy provided by the hot, underlying asthenosphere coupled with compressional stress concen- 
tration in the overlying thin lithosphere could provide additional sources of uplift to make the tectonic inversion of the Araripe Basin viable.

The geodynamic framework proposed in this work to explain the uplift of the Araripe Basin is summarized in Figure (6).

\section{Conclusions}

We have interpreted the high conductivities under the Araripe Basin as an indication of shallow, enriched asthenospheric material, involving small amounts of fluids and melt. We have proposed that the emplacement of a shallow asthenosphere would have originated through extension and passive upwelling at the time of basin formation, and explained its preservation through geologic time by invoking lateral asthenospheric flow from a distant source.

We have proposed that the hot, buoyant asthenospheric material under the basin provided a vertical push under the Araripe Basin that helped the tectonic inversion of the basin. Additionally, the presence of this asthenospheric material under the Araripe Basin - and the correspondingly raised geotherm - might have weakened the lithospheric mantle, caused regional compressional stresses to concentrate on the brittle crust, and contribute to basin uplift.

The high resistivities flanking the conductive anomaly north and south of the Araripe Basin have been interpreted as thickened lithosphere representing lithospheric material that was eroded from under the basin and attached to the flanks through a roll-down flow process.

Shear zones have been mapped as conductive anomalies crossing the crust 
in the Borborema region, suggesting the presence of conductive minerals or graphite, precipitated by fluids flow and shear zone reactivation.

To the south of the profile, the Riacho do Pontal fold belt is observed to be flanked by conductive structures, which have been interpreted as relict subduction material.

\section{Data Availability}

The electromagnetic time series recorded during the BODES experiment, including calibration files and field notes for processing, will be available on the data repository of the PEGBR (http://www.pegbr.on.br) or upon request to the main author.

\section{Acknowledgments}

This work was funded by the Conselho Nacional de Desenvolvimento Científico e Tecnológico (CNPq) through grant $n^{\circ}$ 400743/2014-0. XG thanks $\mathrm{CNPq}$ for the visiting research fellowship held under the Ciência Sem Fronteiras program. JJ also thanks $\mathrm{CNPq}$ for his regular research fellowship (process $\mathrm{n}^{o} 304421 / 2015-4$ ). The authors would like to thank the National Observatory for lending us the instrumentation. We would like to thank Eduardo Menezes, Antônio Vicente, Diogo Coelho and Alessandro Dantas for assistance during data acquisition. Some plots have been generated using the GMT package (Wessel et al., 2013) and Paraview (Ahrens et al., 2005). Comments by editor Nicholas Rawlinson and reviewers Kate Selway and Graham Heinson are greatly appreciated. 


\section{References}

Ahrens, J., Geveci, B., Law, C., 2005. ParaView: An End-User Tool for Large-Data Visualization, in: Hansen, C.D., Johnson, C.R. (Eds.), Visualization Handbook. Elsevier Butterworth-Heinemann. chapter 36, pp. $717-731$

Almeida, Y., Julià, J., Frassetto, A., 2015. Crustal architecture of the Borborema Province, NE Brazil, from receiver function CCP stacks: Implications for Mesozoic stretching and Cenozoic uplift. Tectonophysics 649, $68-80$.

Assine, M., 2007. Araripe basin [bacia do araripe]. Boletim de Geociencias da Petrobras 15, 371-389.

Assumpção, M., Heintz, M., Vauchez, A., Silva, M., 2006. Upper mantle anisotropy in SE and Central Brazil from SKS splitting: Evidence of asthenospheric flow around a cratonic keel. Earth and Planetary Science Letters 250, 224-240.

Assumpção, M., Schimmel, M., Escalante, C., Roberto Barbosa, J., Rocha, M., Barros, L.V., 2004. Intraplate seismicity in SE Brazil: stress concentration in lithospheric thin spots. Geophysical Journal International 159, 390-399.

Baker, J., Chazot, G., Menzies, M., Thirlwall, M., 1998. Metasomatism of the shallow mantle beneath yemen by the afar plume -implications for mantle plumes, flood volcanism, and intraplate volcanism. Geology 26, 431-434. 
Brito Neves, B.B., 1975. Regionalização Geotectônica do Pré-Cambriano Nordestino. Unpublished phd. thesis. University of Saõ Paulo.

Caldwell, T.G., Bibby, H.M., Brown, C., 2004. The magnetotelluric phase tensor. Geophysical Journal International 158, 457-469.

Caxito, F.d.A., Uhlein, A., Dantas, E.L., 2014. The Afeição augen-gneiss Suite and the record of the Cariris Velhos Orogeny (1000--960 Ma) within the Riacho do Pontal fold belt, NE Brazil. Journal of South American Earth Sciences 51, $12-27$.

Caxito, F.d.A., Uhlein, A., Dantas, E.L., Stevenson, R., Salgado, S.S., Dussin, I.A., Sial, A.d.N., 2016. A complete Wilson Cycle recorded within the Riacho do Pontal Orogen, NE Brazil: Implications for the Neoproterozoic evolution of the Borborema Province at the heart of West Gondwana. Precambrian Research 282, 97-120.

Chave, A.D., Jones, A.G., 2012. The Magnetotelluric Method: Theory and Practice. Cambridge University Press, Cambridge.

Chen, C.W., Rondenay, S., Evans, R.L., Snyder, D.B., 2009. Geophysical Detection of Relict Metasomatism from an Archean ( 3.5 Ga) Subduction Zone. Science 326, 1089-1091.

Constable, S.C., 2006. SEO3: A new model of olivine electrical conductivity. Geophysical Journal International 166, 435-437.

Dai, L., Karato, S.i., 2009. Electrical conductivity of orthopyroxene: Implications for the water content of the asthenosphere. Proceedings of the Japan Academy, Series B 85, 466-475. 
Dai, L., Karato, S.i., 2014. Influence of $\mathrm{FeO}$ and $\mathrm{H}$ on the electrical conductivity of olivine. Physics of the Earth and Planetary Interiors 237, $73-79$.

Davies, J.H., 2013. Global map of solid earth surface heat flow. Geochemistry, Geophysics, Geosystems 14, 4608-4622.

de Matos, R.M.D., 1992. The Northeast Brazilian rift system. Tectonics 11, 766-791.

de Matos, R.M.D., 1999. History of the northeast Brazilian rift system: kinematic implications for the break-up between Brazil and West Africa. Geological Society, London, Special Publications 153, 55-73.

Dixon, J.E., Leist, L., Langmuir, C., Schilling, J.G., 2002. Recycled dehydrated lithosphere observed in plume-influenced mid-ocean-ridge basalt. Nature 420, 385-389.

Fetter, A.H., Van Schmus, W.R., Dos Santos, T.J.S., Nogueira Neto, J.A., Arthaud, M.H., 2000. U-PB and SM-ND Geochronological Constraints on the Crustal Evolution and Basement Architecture of Ceará State, NW Borborema Province, NE Brazil: Implications for the Existence of the Paleoproterozoic Supercontinent "Atlantica". Revista Brasileira de Geosciências $30,102-106$.

Green, D.H., Hibberson, W.O., Kovács, I., Rosenthal, A., 2010. Water and its influence on the lithosphere-asthenosphere boundary. Nature 467, 448451. 
Groom, R.W., Bailey, R.C., 1989. Decomposition of Magnetotelluric Impedance Tensors in the Presence of Local Three-Dimensional Galvanic Distortion. Journal of Geophysical Research 94, 1913-1925.

Hamza, V.M., Dias, F.J.S., Gomes, A.J., Terceros, Z.G.D., 2005. Numerical and functional representations of regional heat flow in South America. Physics of the Earth and Planetary Interiors 152, 223-256.

Hashin, Z., Shtrikman, S., 1962. On some variational principles in anisotropic and nonhomogeneous elasticity. Journal of the Mechanics and Physics of Solids 10, 335-342.

Hirschmann, M.M., Tenner, T., Aubaud, C., Withers, A., 2009. Dehydration melting of nominally anhydrous mantle: The primacy of partitioning. Physics of the Earth and Planetary Interiors 176, 54-68.

Jones, A.G., 1987. MT and reflection: an essential combination. Geophysical Journal International 89, 7-18.

Jones, A.G., 2012. Distortion of magnetotelluric data: its identification and removal, in: Chave, A.D., Jones, A.G. (Eds.), The Magnetotelluric Method: Theory and Practice. Cambridge University Press, Cambridge, pp. 219-302.

Kelbert, A., Meqbel, N., Egbert, G.D., Tandon, K., 2014. ModEM: A modular system for inversion of electromagnetic geophysical data. Computers \& Geosciences $66,40-53$.

Knesel, K.M., Souza, Z.S., Vasconcelos, P.M., Cohen, B.E., Silveira, F.V., 2011. Young volcanism in the Borborema Province, NE Brazil, shows no 
evidence for a trace of the Fernando de Noronha plume on the continent. Earth and Planetary Science Letters 302, 38-50.

Liu, M., Shen, Y., 1998. Sierra Nevada uplift: A ductile link to mantle upwelling under the Basin and Range province. Geology 26, 299.

Luz, R.M.N., Julià, J., do Nascimento, A.F., 2015. Crustal structure of the eastern Borborema Province, NE Brazil, from the joint inversion of receiver functions and surface-wave dispersion: Implications for plateau uplift. Journal of Geophysical Research: Solid Earth 120, 3848-3869.

Mancinelli, N.J., Fischer, K.M., Dalton, C.A., 2017. How sharp is the cratonic lithosphere-asthenosphere transition? Geophysical Research Letters 44, 10,189-10,197.

Mareschal, M., Kellett, R.L., Kurtz, R.D., Ludden, J.N., Ji, S., Bailey, R.C., 1995. Archaean cratonic roots, mantle shear zones and deep electrical anisotropy. Nature 375, 134-137.

Marques, F.O., Nogueira, F.C.C., Bezerra, F.H.R., de Castro, D.L., 2014. The Araripe Basin in NE Brazil: An intracontinental graben inverted to a high-standing horst. Tectonophysics 630, 251-264.

Mierdel, K., Keppler, H., Smyth, J.R., Langenhorst, F., 2007. Water Solubility in Aluminous Orthopyroxene and the Origin of Earth's Asthenosphere. Science 315, 364-368.

Mizusaki, A., Thomaz-Filho, A., Milani, E., de Césero, P., 2002. Mesozoic and Cenozoic igneous activity and its tectonic control in northeastern Brazil. Journal of South American Earth Sciences 15, 183-198. 
Morais Neto, J., Hegarty, K., Karner, G., Alkmim, F., 2009. Timing and mechanisms for the generation and modification of the anomalous topography of the Borborema Province, northeastern Brazil. Marine and Petroleum Geology 26, 1070-1086.

Simões Neto, F., Julià, J., Schimmel, M., 2017. Estudo do manto superior com tomografia telessísmica, in: 27th Simpósio de Geologia do Nordeste, João Pessoa, PB. p. REPPB380.

Neukirch, M., Garcia, X., 2014. Nonstationary magnetotelluric data processing with instantaneous parameter. Journal of Geophysical Research: Solid Earth 119, 1634-1654.

Neukirch, M., Garcia, X., Galiana, S., 2017. Appraisal of the Magnetotelluric Galvanic Electric Distortion by Optimisation of the Relation between Amplitude and Phase Tensors. ArXiv e-prints 1704.09020.

Ni, H., Keppler, H., Behrens, H., 2011. Electrical conductivity of hydrous basaltic melts: implications for partial melting in the upper mantle. Contributions to Mineralogy and Petrology 162, 637-650.

Oliveira, R.G.d., de Medeiros, W.E., 2012. Evidences of buried loads in the base of the crust of Borborema Plateau (NE Brazil) from Bouguer admittance estimates. Journal of South American Earth Sciences 37, 6076.

Padilha, A.L., Vitorello, Í., Padua, M.B., Bologna, M.S., 2014. Electromagnetic constraints for subduction zones beneath the northwest Borborema 
${ }_{611}$ province: Evidence for Neoproterozoic island arc-continent collision in northeast Brazil. Geology 42, 91-94.

Padilha, A.L., Vitorello, Í., Pádua, M.B., Fuck, R.A., 2017. Cryptic signatures of Neoproterozoic accretionary events in northeast Brazil imaged by magnetotellurics: Implications for the assembly of West Gondwana. Tectonophysics 699, 164-177.

Peulvast, J.P., Bétard, F., 2015. A history of basin inversion, scarp retreat and shallow denudation: The Araripe basin as a keystone for understanding long-term landscape evolution in NE Brazil. Geomorphology 233, 2040.

Pinheiro, A.G., Julià, J., 2014. Normal thickness of the upper mantle transition zone in NE Brazil does not favour mantle plumes as origin for intraplate Cenozoic volcanism. Geophysical Journal International 199, 9961005.

Jardim de Sá, E.F., Da Trindade, R.I.F., de Hollanda, M.H.B.M., Araújo, J.M.M., Galindo, A.C., Amaro, V.E., de Souza, Z.S., Vigneresse, J.L., Lardeaux, J.M., 1999. Brasiliano Syntectonic Alkaline Granites Emplaced in a Strike Slip/Extensional Setting (Eastern Seridó Belt, NE Brazil). Anais da Academia Brasileira de Ciencias 71, x2-27.

Sarafian, E., Evans, R.L., Collins, J.A., Elsenbeck, J., Gaetani, G.A., Gaherty, J.B., Hirth, G., Lizarralde, D., 2015. The electrical structure of the central Pacific upper mantle constrained by the NoMelt experiment. Geochemistry, Geophysics, Geosystems 16, 1115-1132. 
Schimmel, M., Assumpção, M., VanDecar, J.C., 2003. Seismic velocity anomalies beneath SE Brazil from $\mathrm{P}$ and $\mathrm{S}$ wave travel time inversions. Journal of Geophysical Research: Solid Earth 108.

Shankland, T.J., Duba, A.G., 1990. Standard electrical conductivity of isotropic, homogeneous olivine in the temperature range $1200^{\circ}-1500^{\circ} \mathrm{C}$. Geophysical Journal International 103, 25-31.

Sifré, D., Gardés, E., Massuyeau, M., Hashim, L., Hier-Majumder, S., Gaillard, F., 2014. Electrical conductivity during incipient melting in the oceanic low-velocity zone. Nature 509, 81-85.

Sleep, N.H., 2003. Fate of mantle plume material trapped within a lithospheric catchment with reference to Brazil. Geochemistry, Geophysics, Geosystems 4.

Souza, Z.S., Vasconcelos, P.M., Nascimento, M.A.L., Silveira, F.V., Paiva, H.S., Dias, L.G.S., Thiede, D., Carmo, I.O., 2003. 40Ar/39Ar geochronology of Mesozoic and Cenozoic magmatism in NE Brazil, in: 4th South American Symposium on Isotope Geology, Proceedings, IRD. pp. 691-694.

Storey, B.C., 1995. The role of mantle plumes in continental breakup: case histories from Gondwanaland. Nature 377, 301-308.

Till, C.B., Elkins-Tanton, L.T., Fischer, K.M., 2010. A mechanism for lowextent melts at the lithosphere-asthenosphere boundary. Geochemistry, Geophysics, Geosystems 11, Q10015.

Tommasi, A., Vauchez, A., Daudré, B., 1995. Initiation and propagation of 
${ }_{656}$ shear zones in a heterogeneous continental lithosphere. Journal of Geo${ }_{657}$ physical Research: Solid Earth 100, 22083-22101.

${ }_{658}$ Ussami, N., Molina, E., Medeiros, W., 1999. Novos Vínculos sobre a Evolução ${ }_{659}$ Térmica da Margem Continental Leste do Brasil, in: VII Simpósio Na${ }_{660}$ cional de Estudos Tectônicos, Lençóis - BA. Resumos Expandidos, So${ }_{661}$ ciedade Brasileira de Geologia, Salvador - BA. pp. 20 - 23.

${ }_{662}$ Wang, D., Mookherjee, M., Xu, Y., Karato, S.i., 2006. The effect of water ${ }_{663}$ on the electrical conductivity of olivine. Nature 443, 977-80.

${ }_{664}$ Wessel, P., Smith, W.H.F., Scharroo, R., Luis, J., Wobbe, F., 2013. Generic ${ }_{665}$ mapping tools: Improved version released. EOS Trans. AGU 94, 409-410.

${ }_{666}$ Zhao, C., Yoshino, T., 2016. Electrical conductivity of mantle clinopyroxene ${ }_{667}$ as a function of water content and its implication on electrical structure ${ }_{668}$ of uppermost mantle. Earth and Planetary Science Letters 447, 1-9. 


\section{Figures}

Figure 1. Topographic map of NE Brazil showing the location of the long period MT stations of the BODES experiment. Black line indicates the Borborema Province. The Araripe Basin is indicated as well with a black contour line. Red lines indicate shear zones. Site B11 was not used because of its proximity to B01. Inset plot (upper right corner) shows the location of the topographic map (red) and the extension of the 3D MT inversion model (green).

Figure 2. Geologic map of NE Brazil showing basement rock ages, main tectonic features and the location of the long period MT stations of the BODES experiment. The gray line indicates the contour of the Borborema Province. BP: Borborema Province. AB: Araripe Basin; CSF: Craton Saõ Francisco; RdP: Riacho do Pontal fold belt; TM: Troià massif. Shear zones are labeled in italics. Blue arrows indicate the motion of the volcanic lineaments. Lithological map from the Geological Survey of Brazil - CPRM.

Figure 3. Phase tensor and induction arrows (real part) for the BODES MT responses using the Gadget algorithm at different nominal periods. The phase decomposition results with black line indicating the best strike angle, and the colors indicate the phase values. Red lines indicate mapped shear zones.

Figure 4. Slice through the MT sites of the 3D inversion model. Note that the warm colors indicate the presence of conductors, while cold colors indicate the presence of resistors. Yellow labels inside the model are referenced in text. The projection use for the modeling is a UTM, ellipsoid WGS84, zone 24M. BP: Borborema Province; SFC: Saõ Francisco Craton; RTJ: Recôncavo- 
Tucano-Jatobá Basin; A: Araripe Basin; RdP: Riacho do Pontal fold belt; TM: Troiá massif; PSZ: Pernambuco shear zone; PAZ: Patos shear zone; SPFZ: Senador Pompeu shear zone; TF: Tatajuba fault.

Figure 5. Plot of the electrical conductivity as a function of water and melt (Ni et al., 2011), for a mantle initially composed of 60\% Ol, 25\% Opx and $15 \%$ Cpx as suggested by (Sarafian et al., 2015). The partitioning coefficient between mantle and melt has been fixed at $D_{\text {mantle-melt }}=0.009$ (Hirschmann et al., 2009) and temperature at $1350^{\circ} \mathrm{C}$. Conductivity contours at specific values are shown with a white, dashed line. The conductivity contour for the anomaly considered in this work, $25 \Omega m(0.4 \mathrm{~S} / \mathrm{m})$, is shown as a black line.

Figure 6. Cartoon representing a geological interpretation of the MT profile across the Borborema Basin. Dashed lines indicate the thickening of the lithosphere north and south of Araripe by material attached from the roll-down process. 
Table 1: This table contains the recovered distortion parameters, twist, shear and anisotropy angles, for the BODES data set.

\begin{tabular}{c||c|c|c} 
Site & Twist $[\mathrm{deg}]$ & \multicolumn{1}{|c}{ Shear [deg] } & Anisotropy $[\mathrm{deg}]$ \\
\hline \hline B10 & $-10.69 \pm 12.67$ & $0.52 \pm 13.62$ & $-15.65 \pm 3.61$ \\
NBPB & $12.32 \pm 0.03$ & $-30.70 \pm 0.02$ & $-2.65 \pm 0.11$ \\
B01 & $-63.37 \pm 0.06$ & $-38.48 \pm 0.05$ & $-29.00 \pm 0.24$ \\
B02 & $-44.03 \pm 2.51$ & $4.53 \pm 2.83$ & $35.19 \pm 0.26$ \\
B03 & $18.82 \pm 0.04$ & $-0.57 \pm 0.08$ & $34.71 \pm 0.02$ \\
B04 & $-4.96 \pm 0.07$ & $-11.76 \pm 0.04$ & $-6.69 \pm 0.08$ \\
B05 & $7.69 \pm 0.04$ & $-26.39 \pm 0.03$ & $15.82 \pm 0.31$ \\
B06 & $-18.23 \pm 0.03$ & $7.64 \pm 0.04$ & $19.34 \pm 0.02$ \\
B08 & $-87.30 \pm 0.03$ & $7.80 \pm 0.01$ & $-3.84 \pm 0.02$ \\
B07 & $16.03 \pm 0.20$ & $-35.26 \pm 0.45$ & $21.94 \pm 0.17$ \\
B09 & $-36.42 \pm 0.05$ & $-30.72 \pm 0.03$ & $-21.96 \pm 0.06$ \\
NBPN & $-24.03 \pm 0.06$ & $-38.90 \pm 0.02$ & $-8.39 \pm 0.18$
\end{tabular}




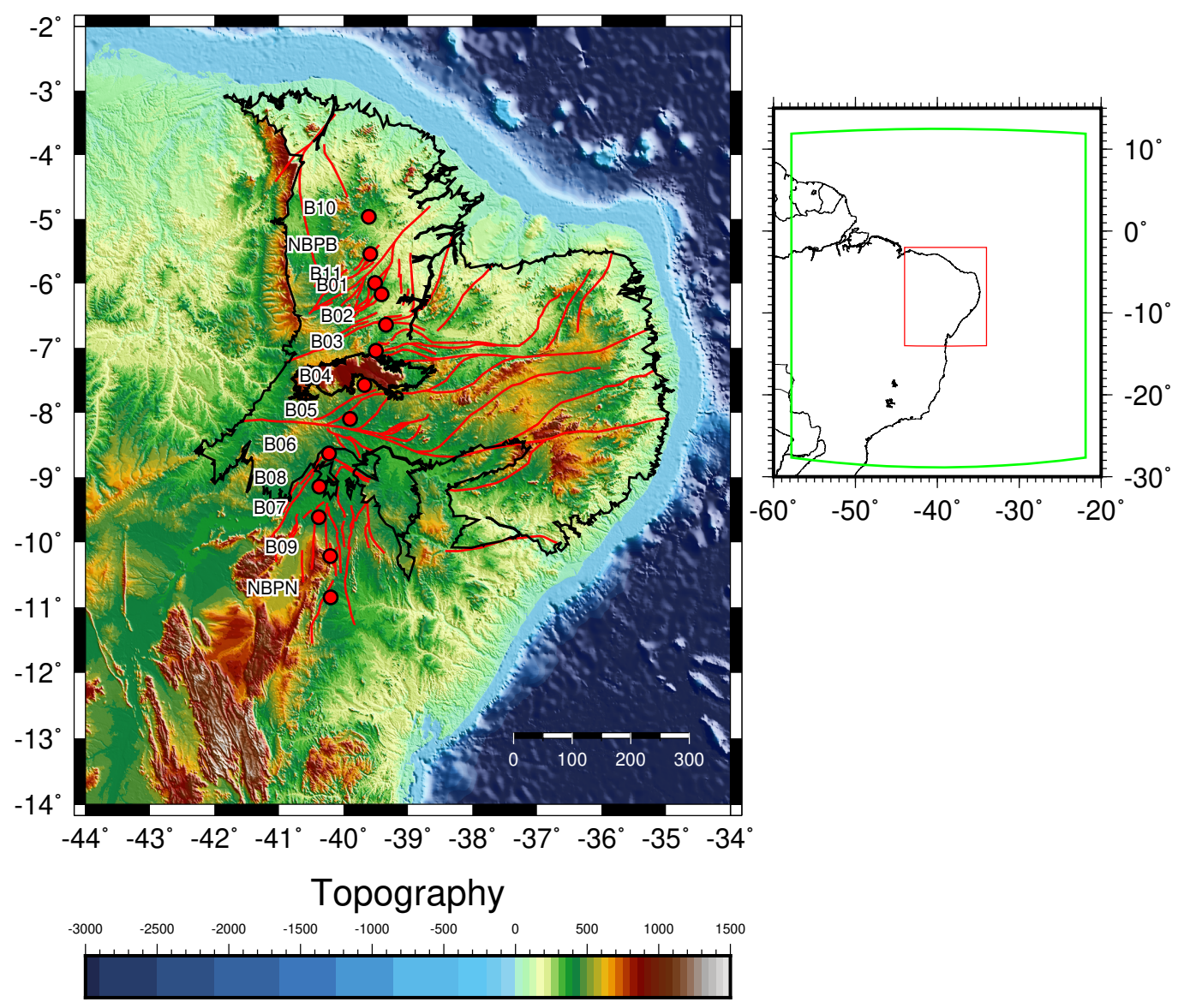

Figure 1: Figure 1. Topographic map of NE Brazil showing the location of the long period MT stations of the BODES experiment. Black line indicates the Borborema Province. The Araripe Basin is indicated as well with a black contour line. Red lines indicate shear zones. Site B11 was not used because of its proximity to B01. Inset plot (upper right corner) shows the location of the topographic map (red) and the extension of the 3D MT inversion model (green). 


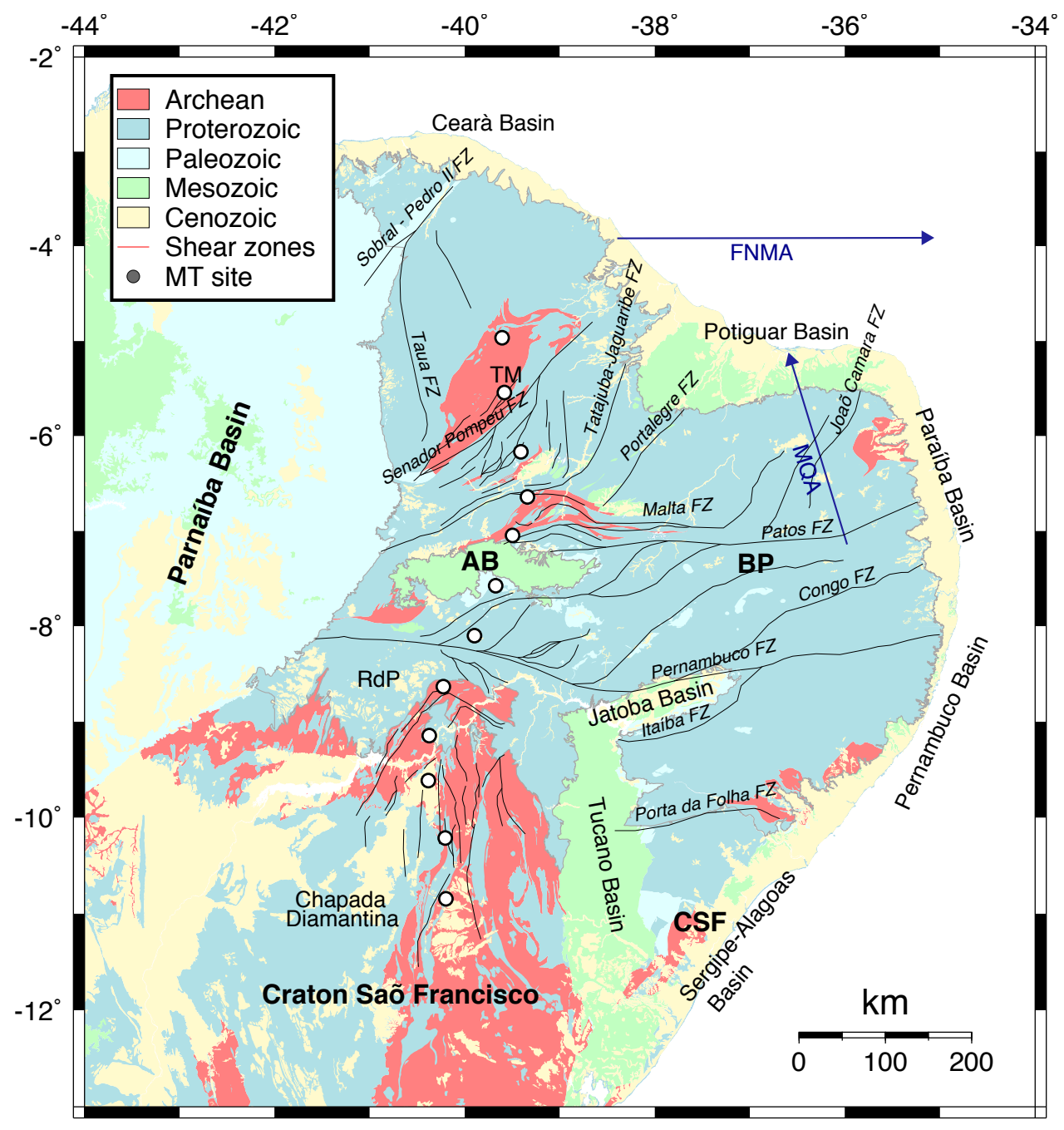

Figure 2: Figure 2. Geologic map of NE Brazil showing basement rock ages, main tectonic features and the location of the long period MT stations of the BODES experiment. The gray line indicates the contour of the Borborema Province. BP: Borborema Province. AB: Araripe Basin; CSF: Craton Saõ Francisco; RdP: Riacho do Pontal fold belt; TM: Troià massif. Shear zones are labeled in italics. Blue arrows indicate the motion of the volcanic lineaments. Lithological map from the Geological Survey of Brazil - CPRM. 


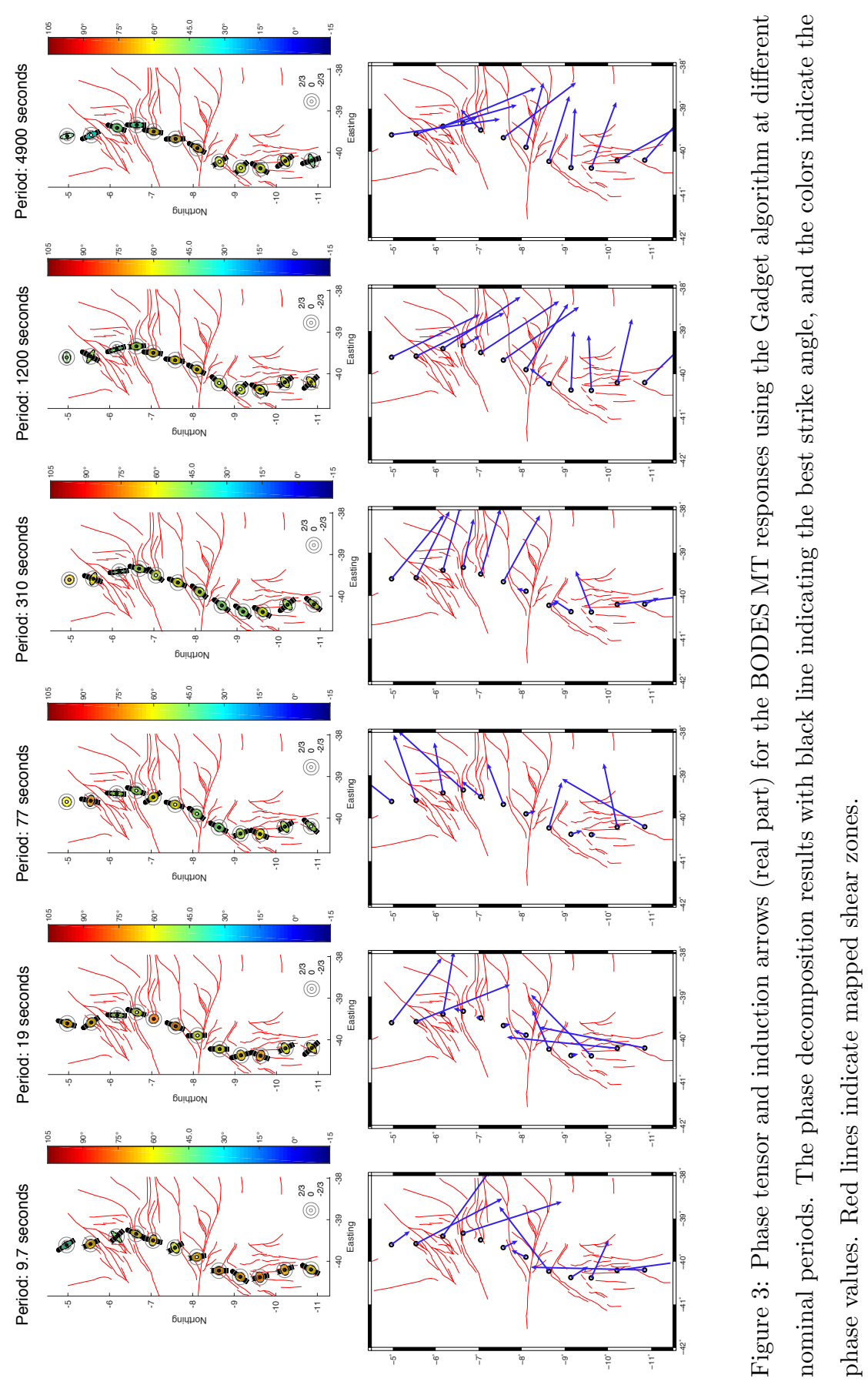




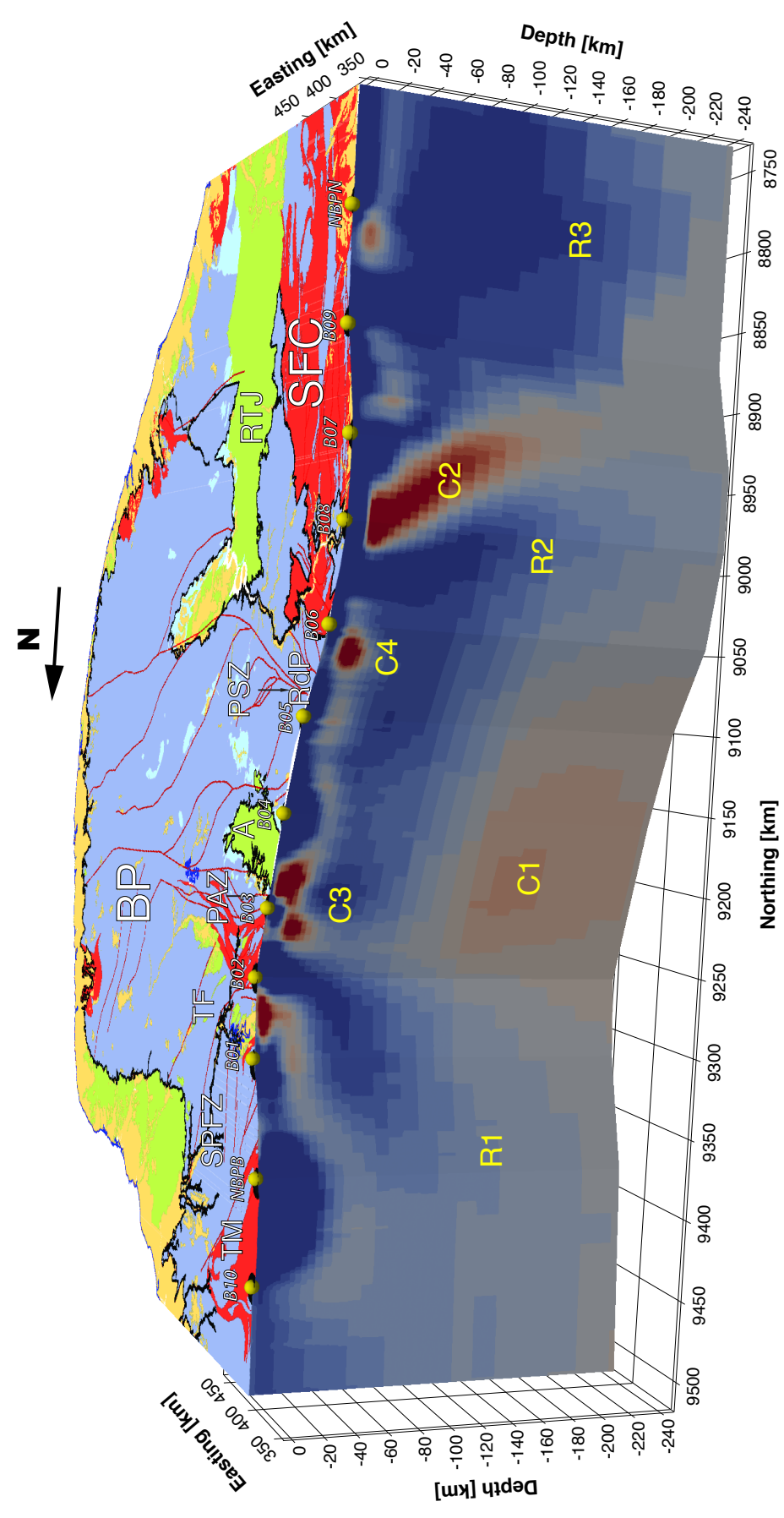

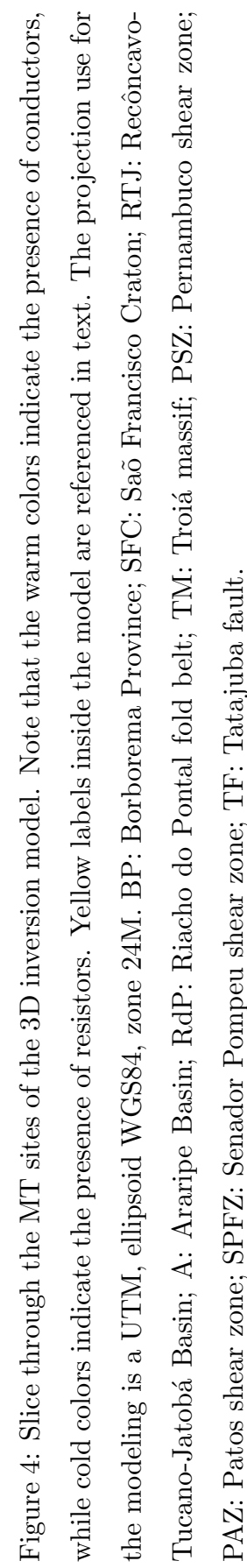




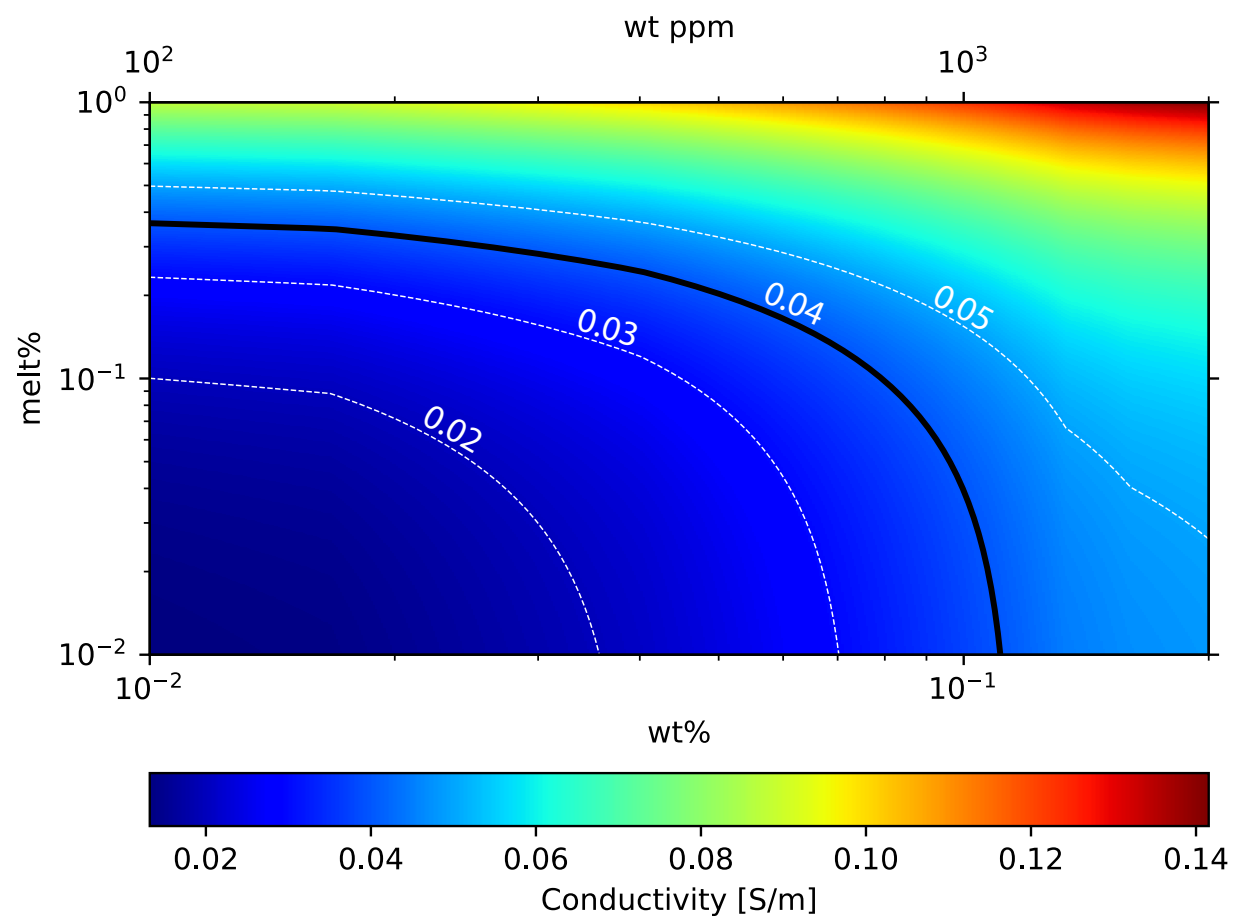

Figure 5: Plot of the electrical conductivity as a function of water and melt (Ni et al., 2011), for a mantle initially composed of $60 \% \mathrm{Ol}, 25 \% \mathrm{Opx}$ and $15 \% \mathrm{Cpx}$ as suggested by (Sarafian et al., 2015). The partitioning coefficient between mantle and melt has been fixed at $D_{\text {mantle-melt }}=0.009$ (Hirschmann et al., 2009) and temperature at $1350^{\circ} \mathrm{C}$. Conductivity contours at specific values are shown with a white, dashed line. The conductivity contour for the anomaly considered in this work, $25 \Omega m(0.4 \mathrm{~S} / \mathrm{m})$, is shown as a black line. 


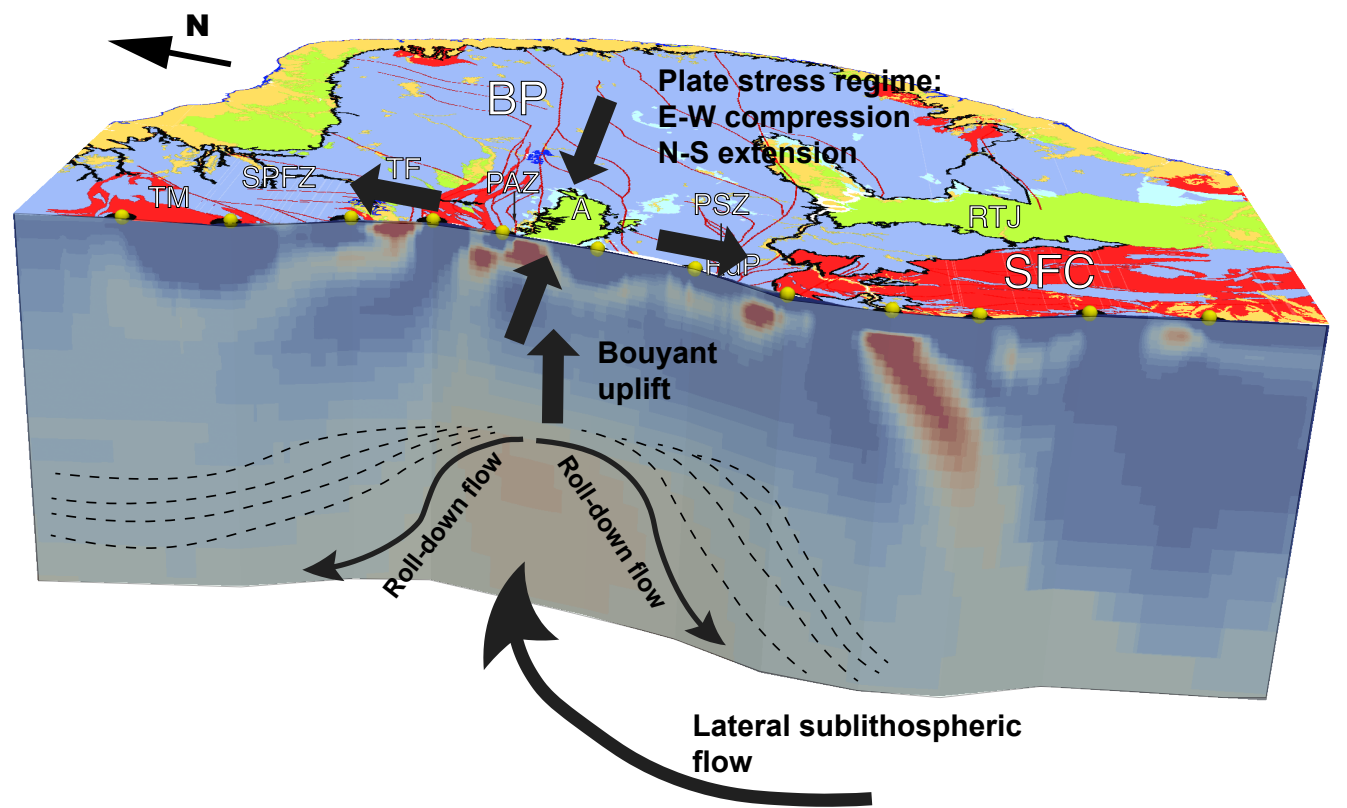

Figure 6: Cartoon representing a geological interpretation of the MT profile across the Borborema Basin. Dashed lines indicate the thickening of the lithosphere north and south of Araripe by material attached from the roll-down process. 